\title{
VALIDATION OF POLITICAL SIMULATION MODELS -WATER RESOURCE PROJECTS ${ }^{1}$
}

\author{
Jonathan W. Bulkley and Julie Antill ${ }^{2}$
}

\begin{abstract}
The critical role of political processes in water resource projects has recently been placed in a new perspective [Hall, 1970]. The "political hassle" period of institutional interaction which serves to resolve political conflicts over such aspects as organizational growth and survival, responsibility for economic liabilities, and responsibility for economic benefits, requires systematic analysis in order to improve our capability to implement water projects. Failure to properly assess the political aspects of a proposed water project may result in extensive delays with significant economic losses. The complexities associated with water use and re-use have created the need for new institutional arrangements which can more effectively function to implement policies and programs.

One tool which has recently become available for the research investigator concerned with institutional interactions and political processes associated with water resource projects is the technique of computer simulation of such institutional interaction. In theory, this new approach will enable the investigator to assess the political feasibility or political acceptability of a proposed water project given existing institutional structures. Furthermore, the investigator has the opportunity to experiment with new and innovative institutional arrangements which may in turn enhance the political acceptability of a proposed project.

The specific material presented within this paper reports upon the validation of an existing computer simulation model designed to replicate political interactions in resource allocation problems-including water resource problems. This validation effort is done by taking an actual water problem and comparing what the political simulation models predicts in terms of political outcomes with what actually takes place. The case study in question is the formulation and legislative development of the Michigan Bond Issue for Water Pollution Control.

(KEY WORDS: political models; simulation models; computer models; political science; Michigan; water pollution control)
\end{abstract}

\section{POLITICAL SYSTEMS}

In abstract terms, a political system is that collection of elements which interact to allocate scarce resources among competing and possibly conflicting uses. Clearly, if a society had access to unlimited resources, there would be little need for political systems to exist in such a society. All human needs and demands for resource allocation would be satisfied from the unlimited resource pool. In reality, demands exceed available resources; therefore, political systems exist to provide choice-making procedures for the allocation of scarce resources among competing potential uses. Water resource projects are particularly good examples of decision-making processes which contain significant political components. While the hydrologic cycle acts to replenish and circulate water within the environment, the distribution of water in the environment is not uniform. In fact, differential demand situations exist such

\footnotetext{
${ }^{1}$ Paper No. 71096 of the Water Resources Bulletin (Journal of the American Water Resources Association). Discussions are open until April 1, 1972. Research supported by the Sea Grant Program, The University of Michigan (National Science Foundation).

${ }^{2}$ Respectively, Assistant Professor and Research Assistant, Department of Civil Engineering, The University of Michigan, Ann Arbor, Michigan 48104.
} 
that certain geographical areas with limited quantities of natural water may be regions of high water demand. Consequently, differential demand conditions coupled with anticipated future increases in demand for water in plentiful quantities and acceptable quality act to create conditions which require a political system for choice-making regarding water projects.

Major water resource projects may be characterized by what has been termed "a political hassle period" [Hall, 1970]. The duration of this period has been observed to range from five to thirty years. The political hassle represents that period of time required to resolve political conflicts associated with the proposed water project. In terms of the abstract definition of political system, the "political hassle" period represents the time required for the political system to interact and resolve the problem of resource allocation among competing and conflicting uses. The importance of the political component of water resource projects is clearly seen if one accepts the observation that the average minimum time required between perception of need and provision of first service is ten years [Hall, 1970]. One expects the political hassle period to account for $30 \%$ to $50 \%$ of the time lapse between need-perception and first service. Consequently, it is of importance to examine the processes which take place during the period of political interaction regarding water projects. Such analysis may lead to more efficient and effective political instruments to reduce the associated time lapse between needperception and first-service.

One research technique which is suitable for analysis of the political interaction associated with water projects is to "model" the political interaction process. The investigator must specify a set of rules which are an attempt to specify the basic processes which the appropriate political system performs during conflict resolution and resource allocation [Maass et al., 1962]. Provided that the investigator has specified the interaction to flow from an initial condition to a terminal point, it is feasible to translate the "model" from verbal to an operational computer simulation model [Males et al., 1970; Bulkley and McLaughlin, 1966].

\section{POLITICAL MODEL: BASIC CHARACTERISTICS}

The political model used in this analysis is composed of six basic elements. These elements constitute a logical model of the political interaction process associated with resource allocation problems. The model is a descriptive model as opposed to a normative model. In essence it is an effort to describe the world of political interaction as it is in contrast to how it should be. The political model is designed to interface with a normative model-especially a linear programming analysis of the resource allocation project under investigation. To date, this interface has not been tested. The basic political theory reflected in the model is that conflict (within bounds) is a useful and actually imperative component of the political process. Conflict assumes that proposed problem solutions are responsive to the needs of the public being affected by the resource allocation project.

The political simulation model is issue oriented. Each of the following elements of the model utilizes data collected by the researcher in the context of a specific issue or resource allocation problem. Associated with each issue will be two or more alternatives which are perceived outcomes or results which would resolve the issue under investigation. The alternatives may or may not be mutually exclusive. The output from the political simulation model in this validation study is a prediction of the political feasibility or political acceptance of what actually was chosen to resolve the issue in question. Since political models clearly do not describe physical processes which proceed from basic natural laws or first principles, the model cannot be expected to produce a deterministic result. Rather, the simulated results are indicators of expected trends. Given the presence of certain random components within the 
model, a distribution of outcomes is obtained. Significance is attached to the $80 \%$ or greater level in predicted outcomes. If the model indicates that the coalitions favoring the proposed allocation "dominate" in $80 \%$ or more of the simulated political interactions, one would interpret these results to indicate that the proposed alternative has a high degree of political acceptance or it is politically feasible. On the other hand if the predicted distribution of dominant coalitions indicates that the concurring coalitions dominate in less than $80 \%$ of the simulated encounters, two interpretations may be attached to the results. First, if the concurring coalitions dominate in less than $80 \%$ but more than $20 \%$ of the simulated political interactions, the political outcome is not clear. More negotiation/bargaining is required among the decision units in order to develop additional alternatives or convince certain of the decision units to alter their priorities. If the concurring coalitions dominate in less than $20 \%$ of the simulated encounters, the proposed alternative is not politically feasible.

\section{POLITICAL MODEL: ELEMENTS}

The six elements which are used to develop this predictive capability are as follows:

(1) Position Matrix: Each of the decision units which can be identified as interacting to influence the decision regarding the specific issue being investigated must have its positions (favorable, ambivalent, opposed) upon the specific issue alternatives reflected in the Position Matrix. This matrix relates decision units with available alternatives and the elements of the matrix represent orientation of the decision unit to each of the available alternatives.

(2) Political Power Coefficient: Each of the decision units has associated with it, a coefficient calculated from data collected by the researcher. This coefficient represents the relative capacity for the particular decision unit to influence the final decision in the specific issue under investigation. This coefficient is not a zero-sum coefficient; however, the summation of all coefficients is equal to one and is assumed to represent the total political power which can be brought to bear upon resolving the issue at the time of simulation.

(3) Conflict Identification: Procedures are incorporated into the model which identify presence or absence of conflict between decision units as a function of the elements of the Position Matrix and as a function of the alternative each decision unit favors for the simulation being performed. This process includes a random component to decide whether or not conflict is present under certain conditions. Coalition formation is a function of the presence or absence of conflict between decision units.

(4) Political Interaction: Each decision unit responds to the proposed solution (alternative) by comparing its individual desires for solving the issue with the proposed solution. Three responses are possible: concurrence (support), opposition, or ambivalence. In the latter case, a random number is utilized to assign ambivalent decision units to either the concurrence or opposition categories.

(5) Coalition Formation: Once the entire population of decision units has been polarized into either support or opposition categories, the process of coalition formation takes place. First, coalition leaders for both the concurring group and the opposing group are selected. Coalition formation takes place when both the coalition leader and potential coalition member are not in conflict with one another-as determined in (3) above. If coalition formation takes place, the political power coefficients of coalition members are added together. The coalition-either concurring or opposing-which amasses the largest aggregate of political power wins (dominates) the particular simulated encounter. Dominant coalitions are recorded.

(6) Generation of Proposed Reallocation: In certain situations, it is relevant to consider a revised solution based upon the political desires of the members of dominant opposition 
coalitions. The model has the capability to generate such a revised solution and test it for political feasibility. Clearly such a proposal would have to be tested for physical/economic feasibility as well.

\section{MODEL VALIDATION}

The critical step following model formulation and computer development is to validate the model. Model validation is accomplished by comparing the simulated results of political interaction obtained from the computer model with actual political results or outcomes in a specific water resource problem. This paper reports upon a validation effort performed upon a specific computer model designed to simulate political interactions associated with water resource projects. The case chosen for model validation is the formulation and implementation of the 1968 Michigan Bond Program for Water Pollution Control. This major water resource program involves the issuance by the State of Michigan of bonds totalling $\$ 335$ million for water pollution control within the State. The plan for the bond project was announced by the Governor of Michigan in early January 1968. The voters approved the proposed bond program in November, 1968; and the enabling legislation was enacted in June, 1969.

Five basic political issues associated with the formulation and enabling legislation stages of the 1968 Michigan Program for Water Pollution Control were chosen for model validation. The results simulated by the political model for these five political issues are compared with the actual political outcomes. These comparisons form the basis for observations regarding the validity and usefulness of the political simulation model. Table 1 and Table 2 list the five political issues examined for model validation. Table 1 specifies two issues which were distinct both in content and in time period. Table 2 identifies one issue which recurred at three distinct time periods during the formulation and legislative stages of the Pollution Control Program. Associated with each issue shown in Table 1 and Table 2 are the realistic alternatives which were perceived to be viable solutions to the specific political issue under examination.

\section{TABLE 1}

Political Issues: Michigan Bond Program - Water Pollution Control

First Issue: Source of Funds for State contribution to water pollution abatement program

Alternatives:

(a) Legislative appropriation each year from the general fund

(b) State borrows funds by selling bonds

(c) State assumes total cost of construction and maintenance of sewage treatment works (use fees and selling bonds)

Second Issue: Should an additional $\$ 50$ million be provided and earmarked for the construction of collecting sewers in smaller, rural communities

Alternatives:

(a) To provide $\$ 285$ million for treatment works and $\$ 50$ million for collecting sewers (rural areas)

(b) To provide only $\$ 285$ million for treatment works 
TABLE 2

Political Issues: Michigan Bond Program-Water Pollution Control

Third Issue: Which unit will determine the allocation of State funds to municipalities (Program Formulation Stage)

Alternatives:

(a) Water Resources Commission (WRC)

(b) State Legislature

Fourth Issue: Which unit will determine the allocation of State funds to municipalities (Early Legislation Period)

Alternatives:

(a) Water Resources Commission (WRC)

(b) State Legislature

Fifth Issue: Which unit will determine the allocation of State funds to municipalities (Late Legisiation Period)

Alternatives:

(a) Water Resources Commission (WRC)

(b) State Legislature

(c) Compromise Solution

\section{POLITICAL SIMULATION}

Issue One: Source of Funds for the Program

In the formulation stage (prior to voter approval) there were four primary decision units interacting to decide upon the method of funding for the State's contribution to the water pollution control program. These four decision units were the following:

The Governor (Governor Romney)

The Water Resources Commission

The Bureau of the Budget

Joint Legislative Committee on Water Resource Planning

This latter group composed of Representatives and Senators had been established in 1965 to study methods of financing sewage treatment works. A report prepared by this committee documented several alternative means of financing sewage treatment facilities. Therefore, even though the actual Committee had completed its task prior to the formulation of the Michigan Program, the Committee is included as a decision unit on the basis of its substantive study and analysis of the problem of financing such activities. The three main methods which were considered for financing the state-wide pollution control program were the following:

1) Appropriation of funds each year by the State Legislature from the General Fund

2) State borrows money by issuing bonds backed by the full faith and credit of the State of Michigan

3) State constructs and operates all new sewage treatment works (user fees and bonds would be required to finance this operation)

As specified in the section of the political model, data was collected which reflected the actual positions of the decision units upon each of these alternatives. Also systematic efforts were undertaken to estimate the actual political power resources associated with each of the 
decision units. Realistic goals of each of the decision units regarding the alternatives were specified. Finally the model was run and a proposed solution was tested for political acceptance. Table 3 lists the results of the simulation run. Each simulation run is composed of 100 simulated political interactions. From Table 3, it is clear that no opposing coalition was able to dominate in any of these simulated interactions. With regard to the concurring coalitionsi.e., the response pattern of decision units which support the proposed solution-the concurring coalitions dominated in all of the 100 simulated political interactions. The number in parentheses following each decision unit is the number of times that the particular decision unit was a member of a dominant coalition. The random components which exist in the model particularly in conflict identification account for the fact that none of the decision units in this case was a member of every dominant coalition. The Joint Legislative Committee opposed the proposed solution but alone was not able to dominate against the coalition patterns generated by the other three decision units which favored the bond method for raising funds. The simulated results are significant as previously defined; one concludes that the bond proposal would be politically acceptable. In the actual case, the bonding method for funding was adopted.

TABLE 3. Results of Simulated Political Interaction*

Issue One: Source of Funds for State Contribution to Water Pollution abatement program

Proposed Solution: State borrows funds by selling bonds

First Simulation: Data representing actual situation

Allocation Opposition (source of funds) - no dominant coalition

Allocation Concurrence

GOV OFFICE (59)

WRC (44)

B BUDGET (50)

JT LEG COM (0)

100/0 Split in favor of proposed solution

$100 / 0$ Split in favor of selling bonds

GOV OFFICE = Governor's Office under the leadership of Governor George Romney unit Jan. 69, then under the leadership of Governor William Milliken

JT LEG COM = Joint Legislative Committee

WRC $\quad$ Water Resources Commission

B BUDGET $=$ Bureau of the Budget

*Example of the results obtained from the model; space requirement precluded display of the same type of information for the remaining issues.

For the purpose of model testing, numerous additional simulation runs were made with each issue. Regarding this Issue, one of these additional simulations was to switch the Governor's position and goal to favoring alternative three. The purpose of this additional run was twofold: first, to test model sensitivity to changes in input data; and secondly, to examine 
a hypothesis that in the early formulation stage, the support of the Governor was critical with regard to political acceptance of a particular alternative. The results obtained suggest that the Governor formed an effective coalition with the Joint Legislative Committee. Specifically, the probability of acceptance of the proposed solution (bonds) was reduced from 1.0 to .43. According to our criteria, this predicted result would indicate that the political feasibility of the proposed solution is questionable. This example is included to indicate the potential for utilization of the model to investigate "what if" inquiries regarding likely behavior on the part of the participating decision units.

\section{Issue Two: Should an additional $\$ 50$ million be provided and earmarked for the construction of collecting sewers in smaller, rural communities}

The technical staff of the Water Resources Commission examined the urban area requirements for waste water treatment facilities through 1980. This analysis indicated that given anticipated Federal contributions through matching grants it would be necessary for the State to raise $\$ 285$ million for the State's portion of the program. During the program's formulation stage, members of special investigating committees in the Legislature were made aware of the very real financial burden being placed upon small rural communities desiring to improve their capabilities to provide effective waste water treatment facilities. Consequently, these legislators with the concurrence of other influential groups decided to propose that the Michigan Bond Program provide an additional $\$ 50$ million for rural communities to build collecting sewers. In the actual situation the issue was resolved in favor of providing the additional funds since it clearly represented a positive-sum situation. The incremental funding would be added on to what had already been determined to be an adequate sum for the urban areas. The political model predicted a high degree of political support for the proposed alternative.

\section{Issue Three, Four, and Five: Which governmental unit will determine the allocation of State funds to municipalities}

The research.effort identified the above stated issue as having been initially considered during the Program Formulation Stage (Issue 3). It surfaced again during the Early Legislation Stage (Issue 4) as the State Legislature attempted to structure the enabling legislation to implement the Pollution Control Program. It required a further appearance (Issue 5) in the Late Legislation Stage to actually resolve the question.

This issue represents several important dimensions of the political aspects of water resource problems. First, it should be clear that the Water Pollution Control Program for the State of Michigan is unique in the history of the State. The governmental unit responsible for allocating the several hundreds of millions of dollars to municipalities may be expected to become a more powerful unit on a state-wide basis. Second, the analysis which sized the fiscal requirements to "adequately" meet the state-wide needs for water pollution control facilities did not consider nutrient removal. Therefore, it is anticipated that the $\$ 285$ million will be considerably less than is actually needed. As a result, the present limited dollar resources will be sought in a competitive fashion by the municipalities of the State. Third, the choice between the Water Resources Commission and the State Legislature as the responsible governmental unit to allocate the State funds reflects the differing perceptions of the method of solution of the water pollution problem. On the one hand, it may be argued that waste water treatment is a technical-engineering problem capable of solution by strictly rational analysis. This is the 
position of those decision units favoring the Water Resources Commission as the responsible unit for allocating Pollution Control program funds. In contrast, another argument states that the allocation of scarce fiscal resources to improve water pollution control is basically a political problem. The proponents of this position will cite the apparent inability of the technical experts to agree upon a single rational analysis of the waste water treatment problem in the State of Michigan. In the absence of rational analysis, political factors need to enter into the decision process. Consequently, the adherents of this latter philosophy conclude that the State Legislature should be the decision unit actually allocating funds to specific projects. This arrangement-in the view of its supporters-would allow for representation of the public interest in pollution abatement through the controlling action of the elected officials.

The distinction between Issues Three, Four, and Five may be clearly drawn. Issue Three represented the problem of designating a responsible unit of government for funding allocation during the problem formulation stage. The twenty participants in this process included thirteen decision units outside of the State Legislature. Issue Four represented the State Legislature's initial attempt to resolve the issue and prepare the enabling legislation. In this case, fifteen decision units were identified as interacting to prepare the legislation. Of these fifteen participating units, ten or two-thirds came from within the Legislature itself. In addition to the fact that different decision units were involved in issue resolution, problem perception is an important distinguishing characteristic. In the formulation stage (Issue Three) the issue may never have to be faced-i.e., the voters may reject the proposal. However, once the voters give overwhelming support to the program and authorize the State to proceed with program implementation, the issue perception changes. The State Legislature recognizes the existence of significant public interest in the problem of water pollution control. Consequently, elements within the State Legislature are anxious to retain control of the actual implementation of the program. Issue Five differs from Issue Four only in the fact that a compromise solution was prepared following the inability of the interacting groups to resolve the conflict in a politically feasible manner in Issue Five.

\section{Issue Three: Which governmental unit will determine the allocation of State funds to municipalities (Program Formulation Stage)}

In this case, the computer model predicted a high degree of political acceptance of the Water Resources Commission being designated the responsible governmental unit for fiscal allocation (Program Formulation Stage). In the actual situation the Water Resources Commission was designated as the responsible unit for funding allocations with little opposition during the program formulation stage.

\section{Issue Four: Which governmental unit will determine the allocation of State funds to municipalities (Enabling Legislation Stage-Early)}

At this point, the legislature addressed itself to the problem of producing the enabling legislation. As previously noted, during the formulation stage, there had been very little opposition to the concept that the Water Resources Commission would be the responsible governmental unit for allocating the funds. However, during the preparation of the enabling legislation the legislature was initially unable to resolve this issue. Fifteen decision units ${ }^{3}$ were

\footnotetext{
${ }^{3}$ A new committee (House-Senate Conference Committee) was created as a result of the impass in the legislature. Accordingly in this simulation, its presence is noted but its capacity for leadership is minimal. The simulation of Issue Five places this committee in its leadership role.
} 
identified as interacting to influence the outcome of this issue. The political simulation model tested the political feasibility of the Water Resources Commission being designated as the unit having prime responsibility for the allocation of state funds. The simulated political acceptability of the proposed course of action declined dramatically from the Issue Three situation. The predicted feasibility of the Water Resources Commission as the unit responsible for funding allocations dropped from $96 \%$ dominance to $55 \%$. Conversely, the opposing units have gained strength from $4 \%$ to $45 \%$ dominance. Simulated results are significant at the $80 \%$ level or greater. Accordingly, the 55/45 split obtained from the simulation model for this issue may be considered to represent the stalemate which actually developed within the legislature.

In the simulation case, the leader of the concurring coalitions was the Governor's office. Membership in this coalition included the House Republicans, House Conservation and Recreation Committee, the House Sponsors of the legislation, the Conference Committee, The Water Resources Commission, and the Bureau of the Budget. The opposition strength was based primarily in the Appropriations Committees in both the Senate and the House. Clearly, these two units would lose the greatest amount of legislative prerogative if the control of project funding passed from the Legislature. Additional support came from the Senate membership as a whole and the House Democrats who opposed the Governor on this issue.

\section{Issue Five: Which governmental unit will determine the allocation of State funds to municipalities (Legislation Stage-Late)}

Late in the enabling legislation stage, the basic problem of designating a responsible unit for fiscal allocation still had not been resolved. In short, the conflict resolution procedures had not been able to obtain a politically feasible solution to Issue Four. Consequently, a special House-Senate Conference Committee was established to develop a compromise solution and resolve the political conflict. Issue Five is the basic problem with the added participation of the House-Senate Conference Committee and a proposed compromise solution to the problem. The proposed compromise was to allow the Water Resources Commission to rank order the projects to be funded on a priority basis. The State Legislature would be given the option of approving or disapproving this proposed list. The State Legislature would not have the power to change the priority ranking of a particular project, but the State Legislature would have the option of not funding a particular project. However, if the Legislature chose not to fund a specific project on the list as prepared by the Water Resources Commission, all projects of a lower priority would also not be funded. This compromise gave the Legislature the authority to draw the line on funding as well as approval or disapproval of the entire list.

Because the Legislature had not been able to agree upon this issue previously, the whole program had been delayed. Consequently, the compromise solution received significant political support in the actual situation. The compromise solution was adopted and placed into the enabling legislation. The simulation model tested the political feasibility of the compromise solution. The simulated outcomes concur with the actual results. The model predicted a 94/6 split in favor of the compromise solution. The political acceptability of the compromise solution resulted from two basic contributing factors. First, it provided a check by the Legislature upon the technical analysis performed by the Water Resources Commission. If a particular municipality believed that its application for state funds had not received an appropriate priority ranking, the municipality would have recourse through the legislature to block approval of the priority rankings-provided that the validity of the complaint was recognized and supported within the legislature. Secondly, the funding program for water pollution control had been delayed while the legislature resolved this issue. Consequently 
pressure existed to overcome the stalemate and produce the workable compromise solution.

\section{CONCLUSIONS}

The major objective of this research effort was to validate an existing computer simulation model by comparing the results of observed situations to those outcomes simulated by the model. The data presented in this paper indicate that the computer model predicted the outcomes of the issues tested in a realistic manner. However it is important to emphasize and reiterate that this type of simulation model cannot be considered to be completely deterministic. Rather, it can be now considered as a potentially useful tool in the examination of political consequences associated with large-scale water resource projects. Additional testing of the model against both historical cases and more importantly with ongoing political conflict issues is necessary.

In addition to the actual validation conclusion, there are a number of related observations which follow from the research effort. First, the presence of the political model necessitated a systematic approach to the collection of data. This requirement by the model insured that the data was organized in a manageable form and that the issues were investigated in a systematic fashion. By requiring the researchers to quantify elements of influence, relationships, and political power, it was necessary to perform a detailed and careful analysis of the interacting decision units. Secondly, it is recognized that certain of the simulated processes as currently performed within the computer model are much too simplified. Further refinement and evaluation of the existing model elements is both necessary and desirable. The model in its present form does provide a tangible set of model elements which can be evaluated and criticized. Third, while only one example was included in this paper, the model demonstrated in numerous additional cases as well logical responsiveness to changes in the input data. Variations of input data related to position, power, and proposed solution produced reasonable changes in the model output. Fourth, the research effort identified the necessity to limit the predictions to the specific issues under investigation. It was found to be impossible to generalize regarding the orientation of any decision unit over a range of several issues. Fifth, in its present form the model does not include time as an explicit parameter. Consequently, it is a static analysis with time fixed as opposed to a dynamic simulation. The researchers believe that the utilization of the model to investigate the development of a specific issue over time (Issue Three, Four, and Five in this paper) will provide extremely useful information to guide the development of a dynamic model from its present static capability.

\section{LITE RATURE CITED}

Bulkley, J. W. and J. A. Antill. 1970. Regional versus local sewage system. Proceedings 13 th Conference on Great Lakes Research. pp. 552-555.

Bulkley, J. W. and R. T. McLaughlin. 1966. Simulation of political interaction in multiple-purpose river basin development. Hydrodynamic Laboratory, Report No. 100, M.I.T. pp. 102-150.

Hall, W. A. 1970. The research interrelationships of the National Water Commission, the Water Resources Council and the Committee in Water Resources Research. Report on 5th Annual Water Resources Research Conference. pp. 7-20.

Joint Legislative Committee on Water Resources Planning. 1966. Study on needs for water pollution control works, State of Michigan. pp. IV-5-IV-8.

Maass, A. et al. 1962. Design of water resource systems. Harvard University. pp. 565-604.

Males, R. M. et al. 1970. A dynamic model of water quality management decision-making. EngineeringScience, Inc. Research and Development Laboratory. pp. IV-1-IV-7. 